DOI:

10.1038/nri1963

\title{
Unlocking $T_{H}$ 17-cell differentiation
}

Dan Littman and colleagues report in Cell that the differentiation of interleukin-17 (IL-17)-producing pro-inflammatory $\mathrm{T}$ helper $\left(\mathrm{T}_{\mathrm{H}}\right)$ cells (known as $\mathrm{T}_{\mathrm{H}} 17$ cells) is directed by the transcription factor and nuclear hormone receptor retinoic-acidrelated orphan receptor- $\gamma \mathrm{t}(\mathrm{ROR} \gamma \mathrm{t})$.

$\mathrm{T}_{\mathrm{H}} 17$ cells are the most recently discovered subset of $\mathrm{T}_{\mathrm{H}}$ cells, and they effect their role at the interface between the adaptive and the innate immune response. They regulate granulopoiesis and host defence against extracellular pathogens, and contribute markedly to the development of autoimmune disease. But what are the mechanisms that regulate the differentiation of this effector-cell subset? Littman and colleagues looked to the orphan nuclear receptor ROR $\gamma$ t to answer this question. ROR $\gamma \mathrm{t}$ is required for development of the lymph nodes, the Peyer's patches and other lymphoid tissues, and the expression of ROR $\gamma \mathrm{t}$ by $\mathrm{CD} 4^{+} \mathrm{CD} 8^{+}$(double positive) $\mathrm{T}$ cells has been shown to extend their survival during clonal selection.

DNA-microarray analysis of $\mathrm{CD}^{+}$ $\mathrm{T}$ cells revealed that culture with IL-23 (which favours differentiation into $\mathrm{T}_{\mathrm{H}} 17$ cells) resulted in an increase in the amount of mRNA encoding ROR $\gamma \mathrm{t}$. Because the authors had already found $\mathrm{ROR} \gamma \mathrm{t}^{+}$ $\mathrm{T}$ cells in the intestinal lamina propria of mice, they were prompted to ask whether these
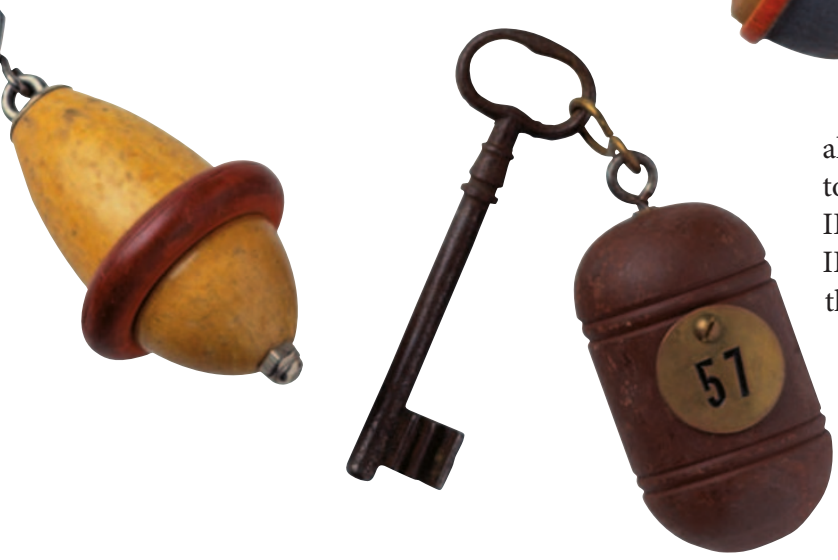
cells were of the $T_{H} 17$ cell subset. A large proportion of lamina propria $\mathrm{T}$ cells were indeed found to produce IL-17, and ROR $\gamma \mathrm{t}$ was required for this

growth factor- $\beta$ (TGF $\beta$ ), cytokines that are known to induce IL-17 expression. Therefore, Littman and colleagues have shown that ROR $\gamma \mathrm{t}$ functions as a transcription factor downstream of IL- 6 and TGF $\beta$ and is required for the differentiation of $\mathrm{T}_{\mathrm{H}} 17$ cells, both in vitro and in the lamina propria.

$T_{H} 17$ cells have been shown to be pathogenic in several animal models of autoimmune disease, including experimental allergic encephalomyelitis (EAE). So the authors induced EAE in both wild-type mice and ROR $\gamma t$-deficient mice, and they examined the role of ROR $\gamma t$ in the development of EAE. Mice that lacked endogenous ROR $\gamma t$ were less susceptible to EAE, and the presence of ROR $\gamma \mathrm{t}$ was shown to be required for the in vivo differentiation of pathogenic $\mathrm{T}_{\mathrm{H}} 17$ cells in the central nervous system during the EAE disease process.

Together, these results indicate that the transcription factor ROR $\gamma \mathrm{t}$ is a key immune regulator that directs the differentiation of $\mathrm{T}_{\mathrm{H}} 17$ cells, which are pro-inflammatory. Manipulating the activity of ROR $\gamma t$ might therefore be an attractive strategy for the treatment of various inflammatory diseases.

Sharon Ahmad were stimulated with antigen, and it was required to induce IL-17 expression by these cells in response to IL-6 and transforming
ORIGINAL RESEARCH PAPER Ivanov, I. I. et al The orphan nuclear receptor ROR $\gamma t$ directs the differentiation program of proinflammatory IL-17 ${ }^{+}$T helper cells. Cell 126, 1121-1133 (2006) 